\title{
REMOVAL OF METHYLENE BLUE FROM AQUEOUS SOLUTION USING ACTIVATED RICE HUSK BIOCHAR: ADSORPTION ISOTHERMS, KINETICS AND ERROR ANALYSIS
}

\author{
*NWORIE, F. S'., NWABUE, F.I ${ }^{1}$, OTI, W., MBAM, E $E^{1}$ AND NWALI, B.U2 \\ ${ }^{1}$ Department of Industrial Chemistry, Ebonyi State University, Abakaliki, Nigeria \\ ${ }^{2}$ Department of Biochemistry Ebonyi State University, Abakaliki, Nigeria
}

\begin{abstract}
Removal efficiency of methylene blue (MEB) from aqueous media was studied under different experimental conditions of pH, contact time and initial concentration of the adsorbate. Activated rice husk biochar (ARHB) was characterized using BET surface area and XRD. The XRD diffraction indicated amorphous nature of the biochar with pore size $(\mathrm{cc} / \mathrm{g})$ and pore surface area $(\mathrm{m} 2 / \mathrm{g})$ of 9.369 and 27.32 respectively from BET surface area plot. Equilibrium isotherm based on coefficient of non- determination indicated the following order as best fit model: Hill $>$ Kiselev $>$ Elovic $>$ Flory-Huggins $>$ Langmuir $>$ Jovanovic $>$ Harkin-Jura $>$ Freundlich $>$ Henry $>$ Temkin $>$ Redlich Peterson $>$ Durbinin-Kaganer Redushkevich $>$ Hill-de Boer $>$ Fowler-Guggenheim. Based on the highest correlation coefficient and the lowest values of the error functions applied to the kinetic models, Weber and Morris intra-particle diffusion and liquid film diffusion were noted to be in control of the sorption rate. The MEB sorption capacity of the activated biochar was $356.99 \mathrm{mmolkg}^{-1}$ which was in the range of commercially available activated carbons and other biosorbents.
\end{abstract}

Keywords: MEB, isotherm models, kinetic models, error analysis, ARHB.

\section{INTRODUCTION}

Poor management and disposal of solid agricultural wastes is the bane of developing nations Nigeria inclusive. The careless and indiscriminate deposition in water bodies, in refuse dumps and combustion of the agricultural solid wastes poses serious threat to ecosystem. The quality of aquatic system including flora and fauna, soil and soil micro-organisms, air and aesthetics are affected adversely presenting itself as a serious environmental concern ${ }^{[1-4]}$. Recently, the development and use of various adsorption materials, techniques and technologies for the removal of contaminants from aqueous media have increased ${ }^{[1-15]}$. Many researchers ${ }^{[15-27]}$ have used many agricultural based waste materials such as Retama Raetam plant, saw dust, wheat bran, Jatropha Curcas and Terminalia Catappa and unmodified saw dust as an alternative cheaper and affordable substitute for application as sorbent for adsorption of contaminants from aqueous media. Rice husks are waste materials from rice processing and are usually discarded indiscriminately or burnt sometimes leading to eutrophication and green house aerosols, carbon (IV) oxide, carbon(II)oxide, methane, nitrogen oxides and volatile organics which present serious health and climatic changes ${ }^{[27-36]}$

Varieties of synthetic anionic and cationic dyes are routinely used by chemical industries such as leather, textile, printing, food, pulp and paper ${ }^{[27]}$. The dyes which are of enormous quantity and usually coloured are released into water bodies as effluents. Studies ${ }^{[28]}$ reported that over eight thousand tons of commercial dyes are manufactured yearly of which azo dyes constitute over fifty percent of the entire produce. The manufacture, utilization and migration of azo dyes poses serious threat to ecosystem since it has complex aromatic structure resistant to biodegradation or structural modification on exposure to light, temperature or common oxidizing agents ${ }^{[27]}$. The non- degradability of azo dyes leads to bioaccumulation in organisms and could be responsible for various dysfunctional observations such as shock, cyanosis, vomiting, tissue necrosis and increased heart beat ${ }^{[7,27]}$. Recently, due to their hazardous, deleterious and chromogenic nature, attention of researchers and those in the industry has been on the rise on how to completely eliminate industrial effluents associated with dyes. Various methods have been applied for the removal of dyes and include chemical coagulation, oxidation, flocculation, ozonation, biological process, membrane based separation method, photocatalytic process, sonochemical process, electrochemical process and adsorption ${ }^{[28-35]}$. Comparison of the methods by researchers ${ }^{[5,27]}$ for dye removal implicated adsorption as the most efficient, effective and green. Similarly, among the sorbents, activated carbon has shown promising outcome and extensively studied but its high cost is a strong limitation to researchers prompting a search for an alternative low cost sorbent of equivalent effectiveness, efficiency and environmentally benign.

To arrest the dangers posed by indiscriminate MEB disposal from industries, rice husk biomass was converted into an activated biochar and used as an economical, effective and environmentally benign solid adsorbent capable of decontaminating aqueous media due to its high adsorption capacity, increased surface activity, surface area ${ }^{[6]}$ and amorphous nature. The use of activated biochar for adsorption could be regarded as a control technique that is environmentally friendly and removes environmental toxicants at low concentration from aqueous media such as waste water, effluents and drinking water.

To understand the adsorption process involving mass transfer and surface interaction, one, two and three adsorption isotherm models were applied as well the kinetic models for a better optimization of the industrial design with incorporation of error of analysis to further strengthen the applicability of the adsorption process. The objective of the present study include (i) to prepare an activated biochar of rice husk biomass and characterize it using x-ray diffraction(XRD and Braunauer-Emmett-Teller (BET) surface area to ascertain the nature of the surface a key function of its suitability for use in adsorption (ii) to determine the adsorption performance of the sorbent for a cationic dye, MEB and assess the adsorption conditions thereof (iii) to evaluate the sorption mechanism of MEB onto the ARHB (iv) to assess the applicability of the sorption mechanism in the process design using error analysis.

\section{MATERIALS AND METHODS}

\section{Adsorbent}

Rice husk was collected from Abakaliki rice mill in polyethene bags and thereafter cleaned, washed severally with double distilled water and dried under the sun and then in a temperature of $105^{\circ} \mathrm{C}$ for $5 \mathrm{~h}$ in an oven. Exactly $400 \mathrm{~g}$ of the dried biomass was subjected to pyrolysis at $550{ }^{\circ} \mathrm{C}$ in a $\mathrm{N}_{2}$ environment in a furnace for $2 \mathrm{~h}^{\text {[39] }}$. The formed biochar were removed, ground into powder, sieved, rinsed with double distilled water and finally dried at $60{ }^{\circ} \mathrm{C}$. Activation of the biochar was effected using a portion of the carbonized rice husk biochar and $1 \mathrm{M} \mathrm{HNO}$ added with continuous stirring for $1 \mathrm{~h}$ as described elsewhere 40]. The mixture was diluted with double distilled water and decanted several times and then washed with double distilled water until the $\mathrm{pH}$ was tested to be 7. The activated biochar was then dried in an oven (Model DHG) at $110^{\circ} \mathrm{C}^{[40]}$ and kept for further studies.

Surface area and pore size were determined using Braunauer-EmmettTeller (BET) Micrometrics ASAP 2020 system. The sample for BET was first dried under vacuum (10-4 bar) at $127^{\circ} \mathrm{C}$ for $20 \mathrm{~h}$ and then degassed under ultrahigh vacuum (10-9 bar) at $120{ }^{\circ} \mathrm{C}$ for $16 \mathrm{~h}$. The sample was back-filled with nitrogen, transferred to the analysis system, and then again degassed under ultrahigh vacuum at $100{ }^{\circ} \mathrm{C}$ overnight. The morphology of the adsorbent was determined with Bruker ${ }^{\circledR}$ D8 Discover X-ray diffractometer, equipped with a Lynx Eye detector, under $\mathrm{Cu}-\mathrm{Ka}$ radiation $(11 / 41.5405 \AA)$ and data collected in the range of $2 \theta=10$ to $100^{\circ}$, scanning rate at $0.010^{\circ} \mathrm{min}^{-1}, 192 \mathrm{~s}$ per step and samples placed on a zero background silicon wafer slide. Proximate compositions of the biochar (ash, protein, nitrogen) were determined using Kjeldahl method ${ }^{[41]}$ whereas the lignin and cellulose content were determined as described elsewhere ${ }^{[42]}$.

The chemicals were of analytical grade and purchased from 
Merck (Germany). MEB (3, 7-bis(dimethylamino)-phenazathionium tetramethylthionine chloride of molecular formula $\mathrm{C}_{16} \mathrm{H}_{18} \mathrm{~N}_{3} \mathrm{SCl} .3 \mathrm{H}_{2} \mathrm{O}$ and molecular weight $373.9 \mathrm{~g} / \mathrm{mol}$ is shown in Figure 1. Stock solution $(100 \mathrm{mg} \mathrm{dm}$ ${ }^{3}$ ) of MEB was made by dissolving a measured exact amount into $\mathrm{pH}$ solution of 7. Solutions for other studies were taken and diluted as required before use.<smiles></smiles>

Figure 1: Structure of MEB.

\section{Batch sorption studies}

Investigation into the sorption of MEB onto ARHB was carried out using batch extraction method. Exactly $0.1 \mathrm{~g}$ of ARHB was measured into a series of $250 \mathrm{~cm}^{3}$ conical flasks with $10 \mathrm{~cm}^{3}$ MEB solution of different concentrations $\left(3.1-7.75 \times 10^{-6} \mathrm{mg} \mathrm{dm}^{-3}\right)$ added previously and at $\mathrm{pH}$ of 6.7. The conical flasks containing the mixture were equilibrated mechanically in a mechanical shaker (Remi equipment) at fixed speed of $150 \mathrm{rpm}$ and $303 \mathrm{~K}$ for $150 \mathrm{~min}$ to attain equilibrium. The conical flask containing the mixtures were removed at predetermined intervals of time, filtered using Whatman filter paper No 1 and centrifuged at $5000 \mathrm{rpm}$ for $4 \mathrm{~min}$ using Gulfex medical scientific England centrifuge model 800D and concentration of MEB determined spectrophotometrically at wavelength of $670 \mathrm{~nm}$ using Jenway Uv - Vis spectrophotometer model 6105.The effect of $\mathrm{pH}$ on the adsorption of MEB onto the rice husk biochar was studied by varying the $\mathrm{pH}$ from 1- 10 effected using $\mathrm{HCl}$ and $\mathrm{NH}_{3}$ while keeping other parameters constant. Exactly $0.1 \mathrm{~g}$ of the ARHB was mixed with $10 \mathrm{~cm}^{3}$ of $7.75 \times 10^{-6} \mathrm{mg} \mathrm{dm}^{-3}$ MEB and treated as described elsewhere ${ }^{[41]}$.

The amount of MEB removed at equilibrium $\mathrm{q}_{\mathrm{e}}(\mathrm{mg} / \mathrm{g})$ was evaluated using equation 1, the percentage MEB (\%) sorbed by ARHB evaluated using equation 2 while the quantity of MEB adsorbed at time $t$ by AHRB $q_{t}(\mathrm{mg} / \mathrm{g})$ was evaluated from equation 3 .

$$
q_{e}=\frac{\left(C_{o}-C_{e}\right) V}{M}
$$$$
\% M E B \text { sorbed }=\frac{C_{o-} C_{e}}{C_{o}} \times 100
$$$$
q_{t}=\frac{\left(C_{o}-C_{t}\right) V}{M}
$$

Where $\mathrm{Co}(\mathrm{mg} / \mathrm{L}), \mathrm{Ce}(\mathrm{mg} / \mathrm{L}), \mathrm{Ct}(\mathrm{mg} / \mathrm{g}), \mathrm{V}(\mathrm{L})$ and $\mathrm{M}(\mathrm{g})$ represents the initial concentration of MEB, equilibrium concentration of MEB, concentration of MEB at time $t$, volume of aqueous media and mass of the dry sorbent respectively. Adsorption processes was modeled using one, two and three parameter linear adsorption models of Hill, Kiselev, Elovic, FloryHuggins, Langmuir, Jovanovic, Harkin-Jura, Freundlich, Henry, Temkin, Redlich Peterson, Durbinin-Kagamer Redushkevich, Hill-de Boer, FowlerGuggenheim. The kinetics of sorption of MEB onto ARHB was studied by plotting the equation of line best fit applied to pseudo-first order, pseudosecond order, Elovich, Weber and Morris, Bangham and Liquid film diffusion models. To estimate the adequacy, applicability, design and best fit model for the process, error analysis was performed using sum square errors, average relative error, standard error of estimate, coefficient of determination, coefficient of non- determination, non-linear-chi square test and Marquardts percentage standard deviation. The itemized experiments were conducted in triplicates and mean values were found reproducible and applied in further analysis of data.

Point of zero charge determination $\mathrm{pH}_{\text {tpe }}$

The sorbent dependence on the surface nature and charge of the adsorption process was done as described elsewhere ${ }^{[27]}$ with slight modification in $\mathrm{pH}$ adjustment using $0.1 \mathrm{M} \mathrm{HCl} / \mathrm{NH}_{3}$ instead of $0.1 \mathrm{M} \mathrm{HCl} / \mathrm{NaOH}$ solutions. The value was determined to be 6.7 .

\section{RESULTS AND DISCUSSION}

Nature of sorbent

The chemical proximate composition of ARHB was determined using Kjeldahl method ${ }^{[39]}$ and the result indicated that it contains high percentage of lignin and cellulose of $39.91 \%$, ash content of $47.0 \%$, protein content of $11.29 \%$ and nitrogen content of $1.80 \%$. The result obtained on the percentage of lignocellulosic polymers was consistent with the study of Kezerle et al., ${ }^{[39]}$.

To investigate the nature of the surface of ARHB in relation to its adsorptivity, BET surface area was performed. Surface area and pore size of the ARHB determined from BET surface area plot are $9.369 \mathrm{cc} / \mathrm{g}$ and 27.32 $\mathrm{m}^{2} / \mathrm{g}$ respectively and represented in Figure 2 . The XRD patterns of ARHB (Figure 3) contained only a broad peak that is characteristic of amorphous phase silica common among biochars carbonized below $600^{\circ} \mathrm{C}(38)$. BET surface area analysis and XRD analysis of ARHB showed amorphous nature and nanosize forms of the biochar respectively ${ }^{[2,12,49]}$. Studies ${ }^{[2]}$ have shown that physicochemical characteristics like surface area and $\mathrm{pH}$ influence environmental usefulness, sorption capacity and applicability of biochars. The large adsorption capacity of the MEB could be as a result of the large surface area and amorphous nature of the ARHB leading to improved capacity to capture the dye from the media ${ }^{[12,42]}$.

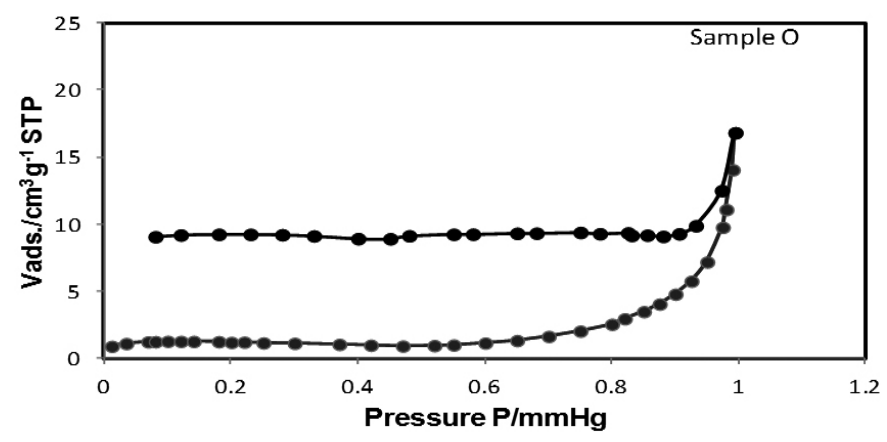

Figure 2: BET surface area of ARHB.

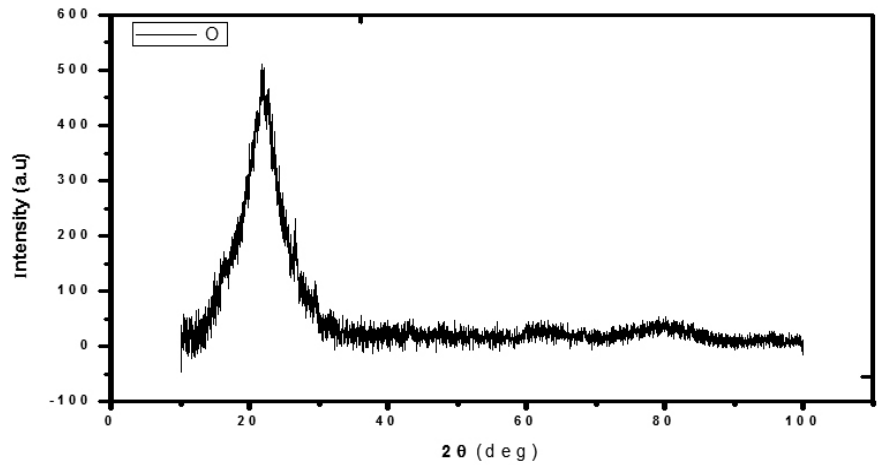

Figure 3: X-ray diffraction pattern of ARHB.

pH effect on the adsorption of MEB

One of the most significant factors that influence adsorptivity potential of biochar is its $\mathrm{pH}^{[2,41]}$. Many characteristics of biochar that influence its capability to capture particulates such as extent of ionization of solution adsorbate, charge on the sorbent surface and sorbent functional groups resident on the reactive sites ${ }^{[43-45]}$. The influence of $\mathrm{pH}$ on the adsorption of MEB onto ARHB was investigated by varying the $\mathrm{pH}$ between $1-10$ at $303 \mathrm{~K}$ for $150 \mathrm{~min}$ and result shown in Figure 4. The highest percentage of the cationic dye MEB adsorbed representing the maximum adsorption capacity was $80.69 \%$ at $\mathrm{pH} 8$ and lowest percentage was $22.8 \%$ at $\mathrm{pH} 3$. Above $\mathrm{pH} 8$, the adsorption remained fairly constant. This observation is consistent with the study by Kezerle et al., ${ }^{[39]}$ on adsorption of MEB onto lignocellulosic wastes. The adsorption was observed to be low at acidic $\mathrm{pH}$ values as against the basic $\mathrm{pH}$ regions as observed in other studies ${ }^{[7,41]}$ probably because of the decreased electrostatic forces of interaction between the surface of ARHB which is positively charged and the cationic MEB. The percentage reduction of adsorption infers competition between the similar charges on both surface of adsorbent and sorbate. Other studies ${ }^{[3,41]}$ on lignocellulosic wastes and retama raetam plant both 
recorded maximum adsorption at $\mathrm{pH} 8$ but their minimum was at $\mathrm{pH} 4$ and 2 respectively. The differences could be that buffered solution was used and could have interfered with the adsorption process. As $\mathrm{pH}$ increased from 6 and above the negative charges on ARHB increased due to increase in negative sites. This led to increased adsorption as electrostatic attraction was increased and $\mathrm{OH}^{-}$presence at the basic region encouraged adsorption. The equilibrium shift as observed could be associated with adsorbent surface functional group dissociation and an alteration on adsorption ${ }^{[22]}$. The point of zero charge of ARHB was determined to be 6.8 and defines the favorable removal of MEB in a given media. Solution $\mathrm{pH}$ greater than $\mathrm{pH}_{\text {zpc }}$ entails cation attraction due to ARHB been negatively charged whereas at solution $\mathrm{pH}$ lower than $\mathrm{pH}_{\mathrm{zpc}}$ means anions are attracted and positive charge on the surface of ARHB ${ }^{[46]}$. Greater $^{\text {zpc }}$ removal of MEB was observed at basic $\mathrm{pH}$ as there is decrease in the number of positive sites and increase in negative charges at the basic $\mathrm{pH}$ region.

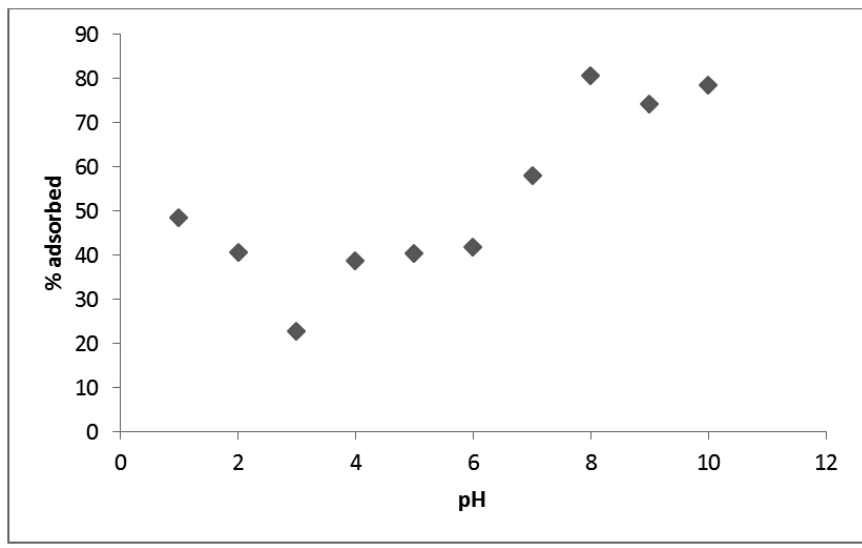

Figure 4: Effect of $\mathrm{pH}$ on the adsorption of MEB.

Effect of initial MEB concentration and time of contact

The initial concentration of adsorbate plays significant role in adsorption studies. The effect of initial concentration of MEB on the adsorption capacity of ARHB was investigated by varying the initial concentration from 3.1 to $7.75 \times 10^{-6} \mathrm{mg} / \mathrm{L}$ and the result displayed in Figure 5. From the plot, it could be observed that the amount of MEB adsorbed increased as the concentration increased. This observation is in line with the studies ${ }^{[38,26]}$ on the removal of MEB through brewers spent mint adsorptive capacity and retama raetam. Sorption capacity increased as the initial MEB concentration increased from $0.095 \mathrm{mg} / \mathrm{g}$ to $0.2 \mathrm{mg} / \mathrm{g}$ and equilibrium was attained indicating increased fractional MEB adsorption. The transport of MEB molecules to interior regions of ARHB controls the adsorption process and liquid film diffusion and intraparticle diffusion mechanisms could be responsible as identified in kinetics studies.

The variation of MEB adsorbed versus time of contact shown in Figure 6 indicated that the adsorption increased with time of contact until equilibrium was reached. There was observed rapid increase in the adsorptive removal of MEB at the initial period with consequent regress near equilibrium. Therefore at the beginning of the adsorption, enough active sites are present and are gradually filled as time increased clogging the sorption sites and an observed reduction or unavailability of free site. The observed increase in MEB removal could be due to the nanosize and amorphous nature of ARHB as large surface area are exposed per unit mass of the ARHB. This observation is in agreement with the studies ${ }^{[15,24,27,41]}$ on the removal of azo dyes from various agricultural waste biochar.

\section{Adsorption equilibrium}

The distribution of MEB between the solid and liquid phases at equilibrium of adsorption estimates to a high extent the adsorption capacity of ARHB, its effectiveness and efficiency and was evaluated using one, two and three parametric models of Henry, Kiselev, Elovic, Flory-Huggins, Langmuir, Jovanovic, Harkin-Jura, Freundlich, Hill, Temkin, Redlich Peterson, DurbininKagamer Redushkevich, Hill-de Boer and Fowler-Guggenheim.

Henry sorption model: The Henry adsorption model a one parametric linear adsorption model operational at low concentration of adsorbate and without consideration of surface coverage is represented in Figure 7 as a plot of $\mathrm{q}_{\mathrm{e}}$ against Ce with linear equation represented in Table 1. The model has correlation coefficient of 0.9476 and coefficient of non- determination of 0.0524 with the $\mathrm{KH}_{\mathrm{E}}$ regarded as Henrys adsorption constant as 94.48 evaluated from Figure 7. The result indicated that the model could not simulate the adsorption process in comparison to other models studied and that since liquid film and intraparticle diffusion control the sorption mechanism, surface coverage is of high consideration and plays significant role.

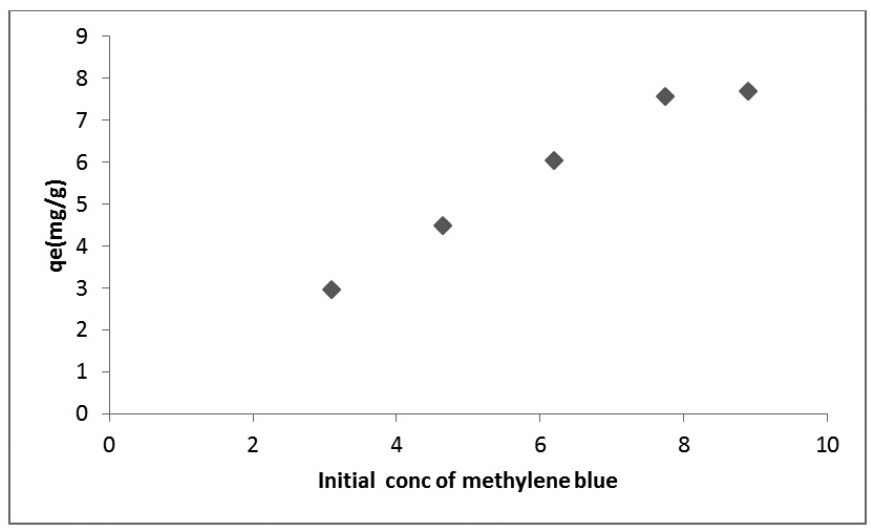

Figure 5: Effect of initial MEB concentration on the adsorption ARHB.

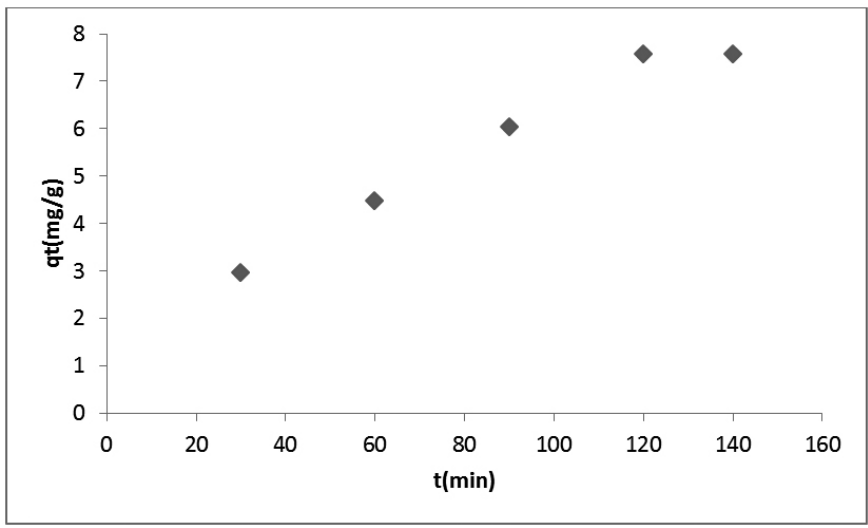

Figure 6: Effect of time of contact on the sorption of MEB onto ARHB.

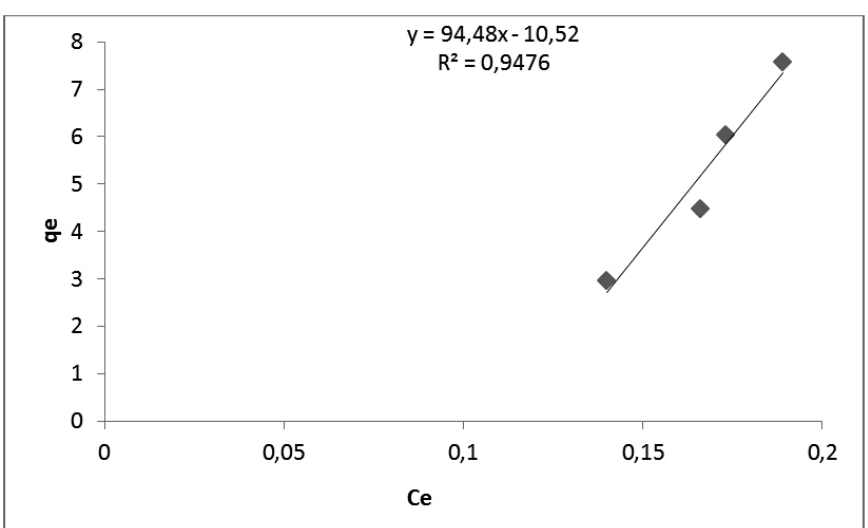

Figure 7: Henrys adsorption isotherm for the sorption of MEB onto ARHB.

Langmuir sorption model: Adsorption is treated as specific to homogenous site, inculcates monolayer coverage without adsorbates in the surface of the adsorbent plane transmigrating due to uniform energy as shown in equation $4^{[27,41]}$. The reversibility of the adsorption and presence of adsorption sites of fixed numbers describes the nature of the model. Linear form of the Langmuir model is shown in Table $1^{[1,27]}$. 


$$
q_{e}=\frac{q_{m} b C_{e}}{1+b C_{e}}
$$

Where $\mathrm{q}_{\mathrm{m}}$ is maximum adsorption capacity of ARHB (mg/g), b the Langmuir constant related to free interaction binding energies of the adsorption $(\mathrm{L} / \mathrm{mg}), \mathrm{q}_{\mathrm{e}}$ the quantity of MEB adsorbed per specific unit mass of ARHB $(\mathrm{mg} / \mathrm{g})$ and $\mathrm{Ce}$ the equilibrium solute concentration $(\mathrm{mg} / \mathrm{L})$

The data simulated using Langmuir equation showed as a plot of Ce/qe versus $\mathrm{Ce}($ Figure 8$)$ shows high correlation coefficient $\left(\mathrm{R}^{2}\right)$ of 0.9807 and indicates very high sorption constant for ARHB(356.99 mmolkg $\left.{ }^{-1}\right)$ which was in the range of commercially available activated carbons(101-395 mmolkg) and other biosorbents (11-680 mmolkg-) ${ }^{[46,49]}$. The dimensionless separation factor $\mathrm{R}_{\mathrm{L}}$ a measure of the desirability and favorability of the model and the Langmuir parameter $\mathrm{b}$ (Langmuir isotherm model constant) was evaluated using Hall equation (Equation 5) ${ }^{[27]}$

$$
\mathrm{RL}=\frac{1}{1+\mathrm{bXo}} \quad 5
$$

Where Xo is the initial MEB concentration. The value of $R_{L}$ is essentially important and defines the isotherm to be linear $\left(R_{L}=1\right)$, unfavorable $\left(R_{L}\right.$ $>1)$ and favorable $\left(0<R_{L}<1\right)^{[1]}$. The study indicated $R_{L}$ value of 0.014 a confirmation that the adsorption of MEB onto ARHB was favorable.

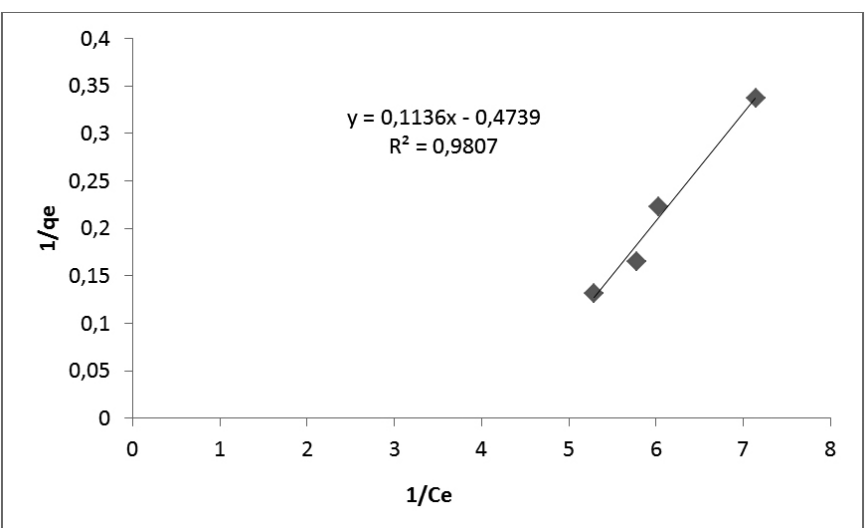

Figure 8: Langmuir isotherm model for the sorption of MEB onto ARHB

\section{Freundlich Isotherm}

Freundlich sorption isotherm model views adsorption to be non-ideal, takes place in a heterogeneous multilayer surface with no limited degree of adsorption sites and energies exponentially or non-uniformly distributed ${ }^{[27,42]}$. Freundlich isotherm is expressed equation in 6 and the linear form in Table 1 , $\mathrm{n}$ is the adsorption intensity representing the favorability of the process and measures the degree at which the model deviates from linearity and $\mathrm{K}_{\mathrm{f}}$ the adsorption capacity representing the adsorptive bond strength obtained as the slope and intercept respectively and shown as the linear plot of In qe against In Ce illustrated in Figure 9. Though the value of correlation coefficient was high 0.9574 and coefficient of non-determination 0.0426 from Table 4 and Figure 9 , the determinant $\mathrm{n}$ value that indicates any variable that projects regress in MEB -ARHB interaction with surface density increase is likely unfavorable $[2,27]$.

The values of $\mathrm{n}$ and $\mathrm{K}_{\mathrm{f}}$ are presented in Table 4 and shows that the Freundlich adsorption process cannot simulate the data since the value of $\mathrm{n}$ is less than one ${ }^{[27]}$.

$$
\mathrm{qe}=K_{F} C e^{1 / n} \quad 6
$$

\section{Temkin isotherm}

This model which is co-operatively applied under the condition of intermediate mode of sorbate concentration considers the fall in the heat of sorption of molecules in the layer to decrease linearly with area of coverage owing to sorbent or sorbate interaction instead of logarithmic ${ }^{[1]}$. The linear form of Temkin isotherm model is shown in equation 7 and in Table 1.

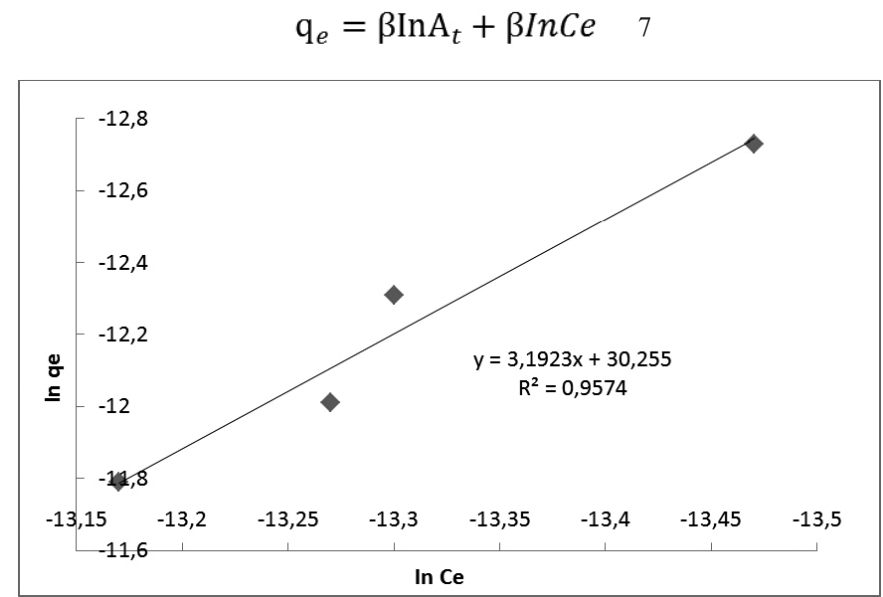

Figure 9: Freundlich isotherm for the sorption of MEB onto ARHB.

From equation 7, $\beta$ is related to the heat of adsorption and $\mathrm{A}$ is the equilibrium binding constant. The plot of $\mathrm{q}_{\mathrm{e}}$ against In $\mathrm{C}$ gives the slope and intercept as $A_{r}$ and $\beta$ respectively. The values of $R^{2}$, coefficient of nondetermination and the constants are presented in Table 4 and Figure 10. The high value of $\mathrm{R}^{2}$ suggests that the model satisfy the experimental data and similar results was obtained in the adsorption of methylene blue with Miswak leaves by another author ${ }^{[27]}$

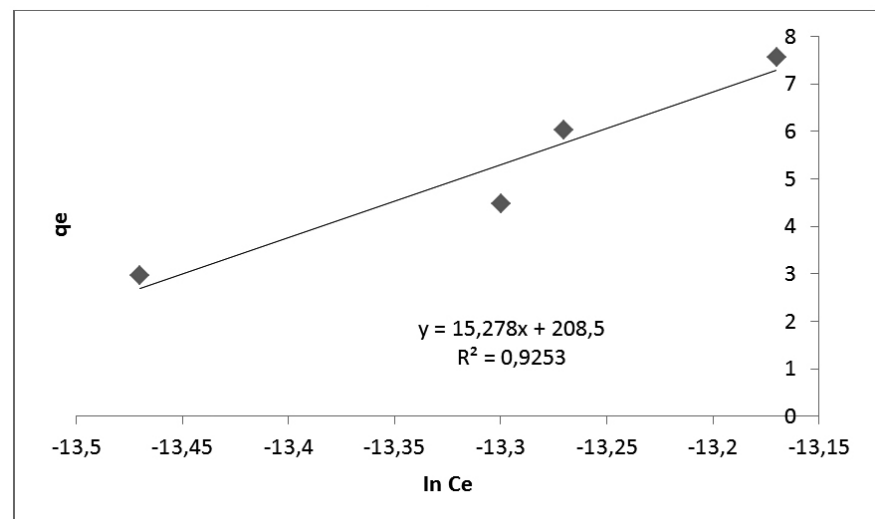

Figure 10: Temkin isotherm plot for the sorption of MEB onto ARHB.

Elovic isotherm model

Elovic model is based on multilayer adsorption and adsorption increases exponentially with adsorption site ${ }^{[1]}$. Elovic isotherm model is represented in equation 8 and the linear form in Table 1.

Elovic constants $\mathrm{Km}$ and $\mathrm{K}_{\mathrm{E}}$ representing maximum adsorption capacity and adsorption constant respectively are evaluated from the slope and intercept of the plot of In $\left(\mathrm{q}_{\mathrm{e}} / \mathrm{C}_{\mathrm{e}}\right)$ versus $\mathrm{q}_{\mathrm{e}}$ (Figure 11 ) and the values shown in Table 4 The value of $\mathrm{R}^{2} 0.9849$ is high with low coefficient of determination of 0.015 as shown in Table 4 but lower than Hill isotherm model which represents monolayer adsorption process. However, the low value of the adsorption capacity as shown in Table 4 indicates that the adsorption does not fit the Elovic model and is not multilayer.

Jovanovic isotherm model: The Langmuir isotherm model is involved with allowance to mechanical interaction. The linear form of the model is shown in Table 1 and the correlation coefficient of 0.9729 obtained from the plot of In $\mathrm{q}_{\mathrm{e}}$ versus Ce (Figure 12) was high enough but lesser than that of Langmuir isotherm model. The simulated data obeyed this model but the observed regress in the value of coefficient of determination in comparison to the Langmuir model presents that absence of mechanical interaction may not be feasible. 


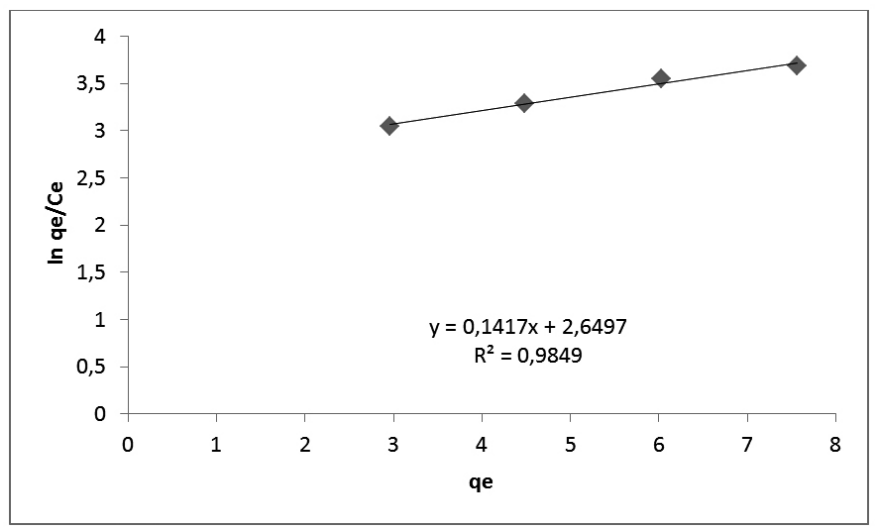

Figure 11: Elovic isotherm model plot for the sorption of MEB onto ARHB.

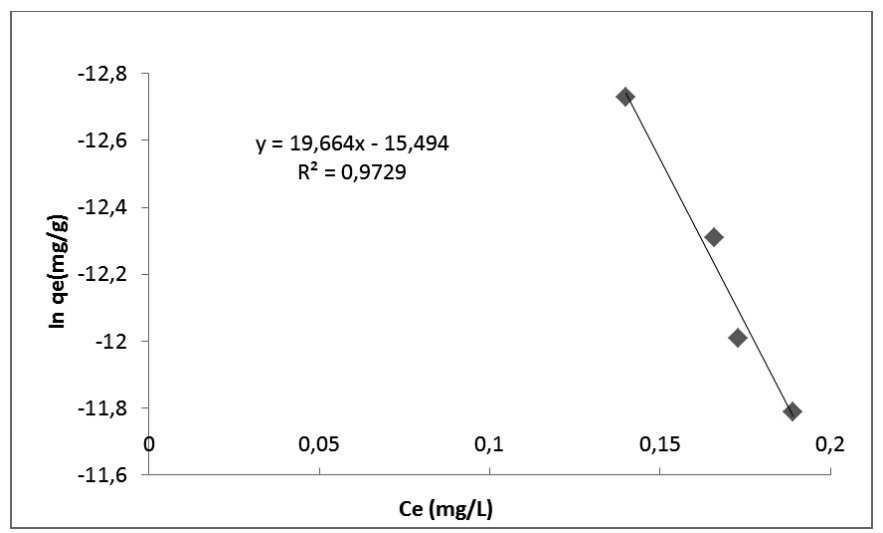

Figure 12: Jovanovic isotherm model plot for the sorption of MEB onto ARHB.

\section{Hill- de Boer isotherm model}

The adsorbing molecules are considered to be mobile with allowance of lateral interaction ${ }^{[6]}$. The linear form of the model is shown in Table 1 with $\mathrm{K}_{1}$ and $\mathrm{K}_{2}$ as Hill-de Boer constant $\left(\mathrm{Lmg}^{-1}\right)$ and energetic constant of the interactional effect between the adsorbed sorbate molecules $\left(\mathrm{KJmol}^{-1}\right)$ respectively. From Table 1, $\Theta, \mathrm{R}$ and $\mathrm{T}$ represents the fractional coverage, the universal gas constant $\left(\mathrm{KJmol}^{-1} \mathrm{~K}^{-1}\right)$ and temperature (T) respectively. From table 4 , the value of $K_{2}$ is positive but very small indicating weak lateral interaction, affinity and attraction between the adsorbed molecules. From the plot of $\operatorname{In}[\mathrm{Ce}(1-\Theta) / \Theta]-\Theta /(1-\Theta)$ versus $\Theta$ (Figure 13), the low value of coefficient of correlation (poor linearization) (0.4723) and as also observed in Fowler-Guggenheim model isotherm (0.3933) makes further interpretation of the model to be avoided and further iterative computer based task to be invoked. The comparison of this model with Fowler-Guggenheim model stems from the fact that Hill - de Boer model verifies assumptions of the earlier model and only applicable to fractional surface coverage evaluated from highest adsorption capacity ${ }^{[6]}$.

\section{Kiselev Isotherm Model}

The model applicable only when the surface coverage $(\Theta>0.68)$ was evaluated from Freundlich model maximum adsorption capacity and inculcates monomolecular localized adsorptive layer. The linear form of the model is shown in Table 1. The plot of $1 / \mathrm{Ce}(1-\Theta)$ versus $1 / \Theta$ (Figure 14) gives the Kiselev equilibrium constant $\left(\mathrm{K}_{\mathrm{i}}\right)\left(\mathrm{Lmg}^{-1}\right)$ and $\mathrm{K}_{\mathrm{n}}$ the equilibrium constant for complexation between adsorbent and adsorbate molecules and represented in Table 4. The simulated data as shown in Figure 14 gives high correlation coefficient value $(0.9855)$ with low coefficient of non-determination (Table $4)$. The value of $K_{n}$ (Table 4$)$ is positive $\left(1.66 \times 10^{-3}\right)$ indicating the formation of complex between the adsorbed species ${ }^{[6]}$ and proved that the model could simulate the data.

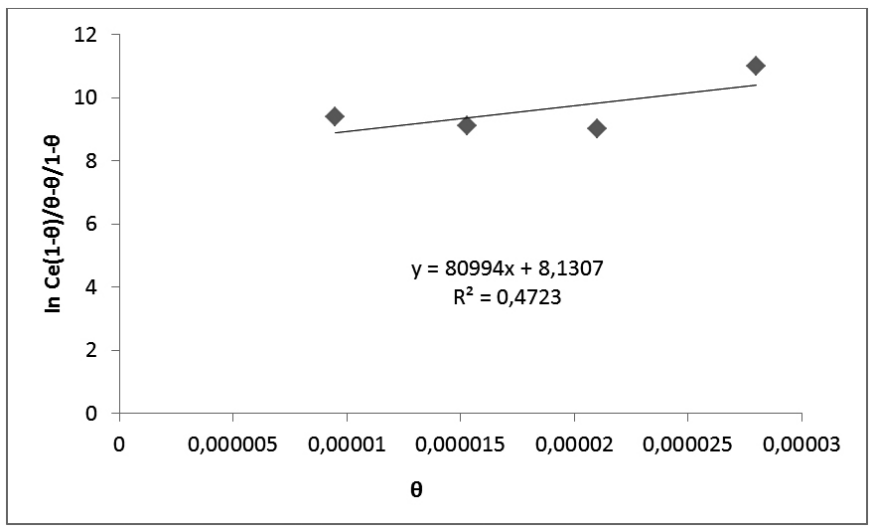

Figure 13: Hill-De boer isotherm model plot for the sorption of MEB onto ARHB.

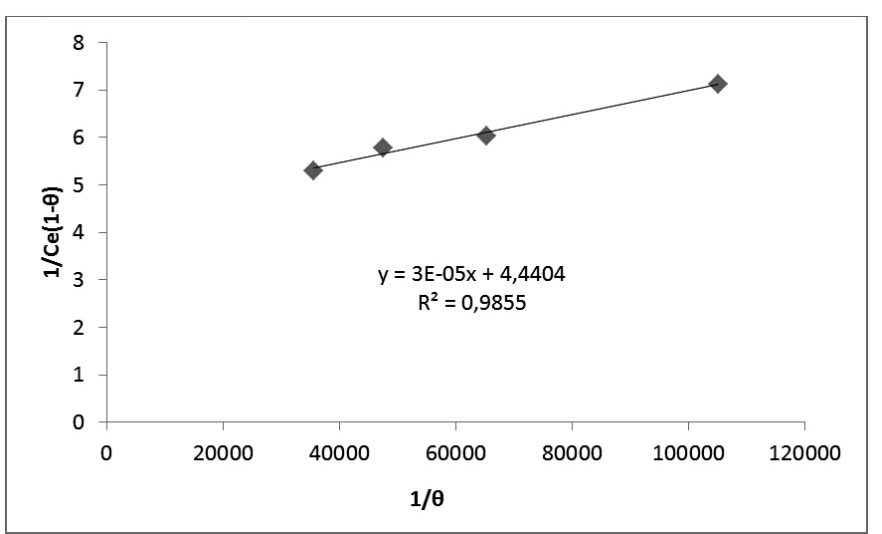

Figure 14: Kiselev isotherm model plot for the sorption of MEB onto ARHB.

\section{Harkin-Jura Isotherm model}

The likelihood of multilayer adsorption due to heterogeneous pore distribution on adsorbent surface is the major consideration of this model ${ }^{[5]}$. The linear form of the model is presented in Table 1.The plot of $1 / \mathrm{qe}^{2}$ versus $\log$ Ce (Figure 15) gave correlation coefficient of 0.9610 with B and A as HarkinJura Isotherm model constants. The $\mathrm{R}^{2}$ value was high but lesser than that of monomolecular adsorption models of Kiselev and could not be the best fit for the adsorption.

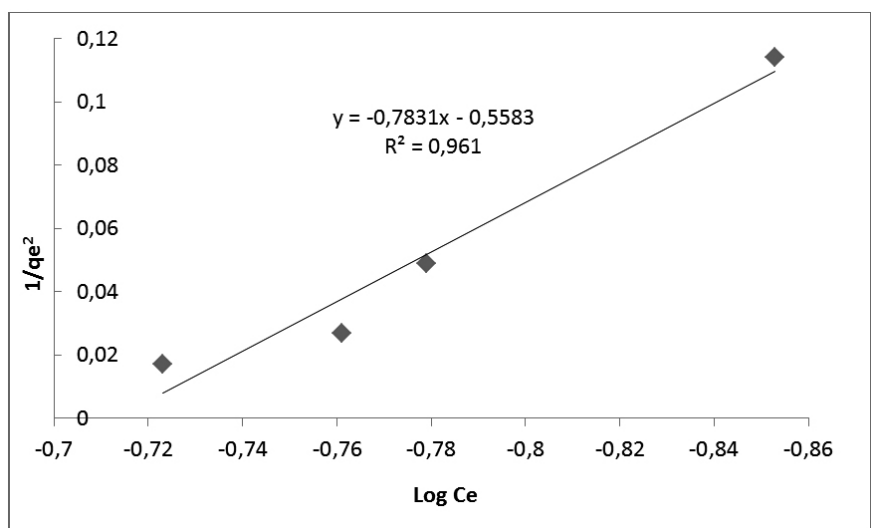

Figure 15: Harkin-Jura isotherm model plot for the sorption of MEB onto ARHB.

Fowler-Guggenheim Isotherm Model

The model takes into account lateral interaction of the adsorbing species within a localized domain with evidenced Van der Waals interactional effect 
between species adsorbed on neighboring sites ${ }^{[4]}$. The energy of interaction or heat of adsorption is constant and the fractional surface coverage of the biosorbent is independent of the heat of adsorption, the entropy exhibited on the molecular distribution of the adsorbate species do not suffer much alteration ${ }^{[6]}$. The surface coverage obtained from Langmuir maximum adsorption capacity is only applicable to the model if $\boldsymbol{\theta}<0.695(6)$. The linear form of the model is shown in Table 1 and the plot of $\operatorname{In} \mathrm{Ce}(1-\boldsymbol{\theta}) / \boldsymbol{\Theta}$ versus $\boldsymbol{\Theta}$ in Figure 16. The constant $\mathrm{K}_{\mathrm{FG}}$ represents the Fowler-Guggenheim equilibrium constant (Lmg${ }^{1}$ ) an interaction between adsorbent and adsorbate molecules, W the heat of adsorption representing the empirical interaction energy of the adsorbed two species existing in close by sites $\left(\mathrm{KJmol}^{-1}\right), \mathrm{R}$ the molar gas constant $(8.314 \mathrm{~J}$ mol- $^{-1} \mathrm{~K}^{-1}$ ), T the thermodynamic temperature $(\mathrm{K})$ and $\boldsymbol{\Theta}$ the fractional surface coverage. From Figure 16, there was observed low correlation coefficient with positive value of $\mathrm{W}$ indicating unattractive and repulsive interaction between the adsorbed molecules ${ }^{[1]}$. This entails the heat of adsorption and the loading of adsorbate species are inversely related an indication that increased loading leads to decreased interaction between adsorbed species ${ }^{[4]}$. In this present case, the poor linearization as obtained further strengthens the inability of the model to simulate the data.

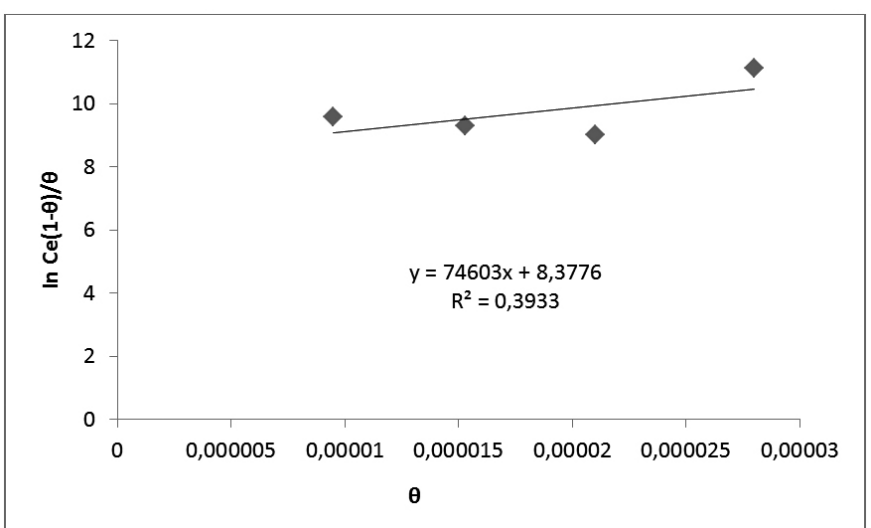

Figure 16: Fowler-Guggenheim isotherm model plot for the sorption of MEB onto ARHB.

Flory-Huggins Isotherm Model

The model considers the extent of surface coverage properties of the adsorbate on the adsorbent material ${ }^{[5]}$ and is expressed linearly as shown in Table 1. From the linear expression in Table 1, $\Theta$ represents the extent of surface coverage, $\mathrm{n}_{\mathrm{FH}}$ the adsorbent number present in the sorption zone and $\mathrm{K}_{\mathrm{FH}}$ the Flory-Huggins constant $\left(\mathrm{Lmol}^{-1}\right)$. Consequently, $\left(\mathrm{n}_{\mathrm{FH}}>1\right)$ indicates multilayer adsorption of molecules on adsorbent surface, $\left(\mathrm{n}_{\mathrm{FH}}<1\right)$ indicates greater than unity active zone of adsorbent would be occupied by adsorbate ${ }^{\left[{ }^{[b}\right.}$ The Gibbs free energy for the spontaneous process evaluated from equilibrium constant $\mathrm{K}_{\mathrm{FH}}$ is represented as equation 9

Where $\Delta \mathbf{G}^{\circ}$ is the standard free energy change $\mathrm{T}$ the absolute temperature and $\mathrm{R}$ the molar gas constant $\left(8.314 \mathrm{Jmol}^{-1} \mathrm{~K}^{-1}\right)$. The low correlation coefficient (Figure 17) obtained and negative $\mathrm{n}_{\mathrm{FH}}$ values (Table 4) show that the model could not simulate the data well and not applicable in explaining the adsorptive process.

$$
\Delta G^{o}=R T \operatorname{In} K_{F H} \quad 9
$$

\section{Durbinin-Kaganer Radushkevich (DKR)}

The adsorption using the semi-empirical DKR equation adopts pore filling process applicable to intermediate concentration range of adsorbate with multilayer, physiosorptive, Van Der Waals and heterogeneous -homogeneous surface involvement with consequent Gaussian free energy consideration ${ }^{[4]}$. The linear form of the temperature dependent model is shown in Table 1 and the plot of Inqe versus $\varepsilon$ represented in Figure 18. The parameter $\varepsilon$ regarded as Polanyi potential is represented in equation 10 and mean adsorption energy $\mathrm{E}$ $(\mathrm{KJ} / \mathrm{mol})$ was evaluated using equation 11

$$
\varepsilon=\operatorname{RTIn}\left\lfloor 1+\frac{1}{C_{e}}\right\rfloor
$$

$$
E=\frac{1}{\sqrt{-2 \beta}}
$$

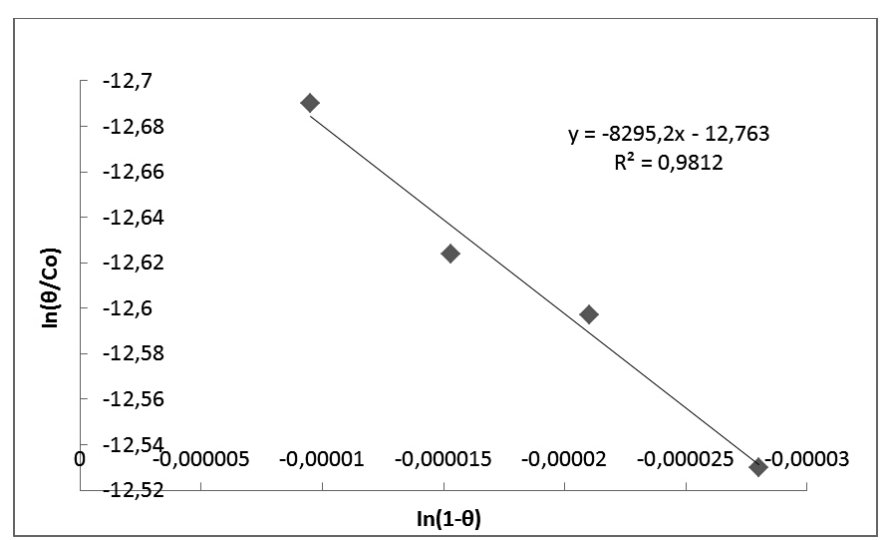

Figure 17: Flory-Huggins isotherm model plot for the sorption of MEB onto ARHB.

$\boldsymbol{B}$ is DKR constant representing mean adsorption energy $\left(\mathrm{mol}^{2} / \mathrm{KJ}^{2}\right)$, $\mathrm{R}$ the molar gas constant $\left(8.314 \mathrm{~J} \mathrm{~mol}^{-1} \mathrm{~K}^{-1}\right), \mathrm{q}_{\mathrm{m}}$ the DKR monolayer adsorption capacity $(\mathrm{mg} / \mathrm{g}), \mathrm{T}$ the absolute temperature(K). The value of $\mathrm{E}$ describes the nature of adsorption either as physical or chemical or ion exchange if the value is less than $8 \mathrm{KJ} / \mathrm{mol}$ or within $8-16 \mathrm{KJ} / \mathrm{mol}$ respectively ${ }^{[27]}$. In the present study, the adsorption energy $\mathrm{E}$ is $0.011 \mathrm{KJ} / \mathrm{mol}$ which is less than 8 $\mathrm{KJ} / \mathrm{mol}$ indicating that at the temperature of $303 \mathrm{~K}$ in which the adsorption was performed, physical processes are predominant and mainly in operation. From Table 4, the coefficient of regression value was high (0.9812) with low coefficient of non-determination indicating that the model simulated the data well but not as Hill isotherm model.

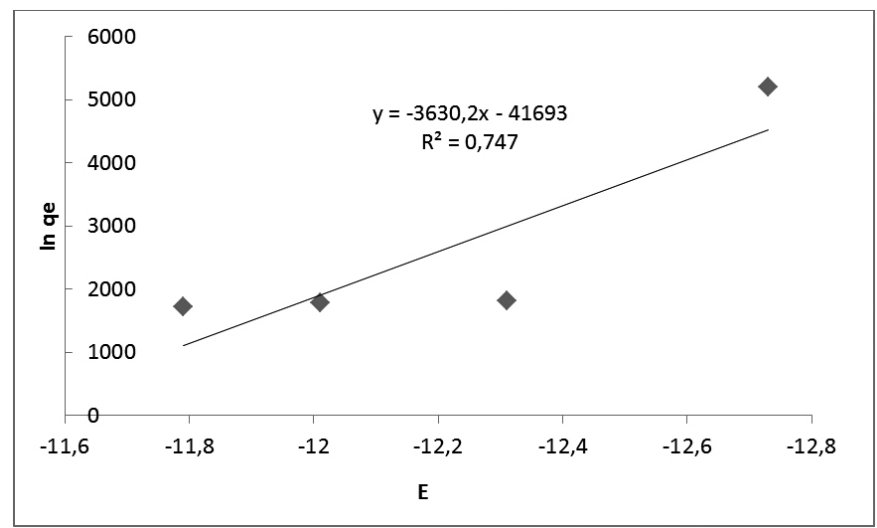

Figure 18: Dubinin-Kaganer-Radushkevich isotherm model plot for the sorption of MEB onto ARHB

\section{Hill Isotherm model}

The model views binding of different molecules to homogeneous surfaces as positive, negative or non-co-operative with adsorbate molecules residing at a particular adsorbent surface significantly influencing separate binding surface on the said sorbent ${ }^{[5]}$. The linear form of the model is shown in Table 1 with $\mathrm{K}_{\mathrm{D}}$ as the Hill dissociation constant and $\mathrm{nH}$ the Hill coefficient for interaction a measure of molecular co-operativity. Co-operativity of the adsorption as defined by slope $(\mathrm{nH}=2.451)$ of the plot of Log qe/1-qe versus Log Co (Figure 18) shows that the complexation of the cationic dye MEB onto the biosorbent ARHB is positive; $\mathrm{nH}$ been greater than unity. The coefficient of regression (0.9998) of the model was the highest among the studied equilibrium model isotherm and suggest that the model is fit and appropriate for industrial designs.

Redlich- Peterson Isotherm model

There is an interplay of Langmuir and Freundlich isotherm models with 
three parametric approaches which deviates from a standard monolayer adsorptivity consideration ${ }^{[4]}$. The model enhances characterization of equilibria of adsorption in a wide range of concentrations as at infinite dilution approachability to Henrys zone due to the numerator emanating from Langmuir is achievable ${ }^{[5]}$. The linear form of the model is presented in Table 1. The adsorptivity capacity constant $\mathrm{A}\left(\mathrm{Lg}^{-1}\right)$, the parameters $\mathrm{B}\left(\mathrm{Lmg}^{-1}\right)$ and $\beta\left(\mathrm{mgL}^{-}\right.$ 1) represents another constant and an exponent $(0<\beta<1)$ respectively. The two limiting conditions of Langmuir and Freundlich isotherms are achieved when $\beta=1$ and $\beta=0$ respectively. From Table 4 and Figure 20 (plot of In $(\mathrm{Ce} / \mathrm{qe})$ versus $\mathrm{In} \mathrm{Ce})$, the value of $\beta$ is approximately unity $(0.98)$ and with high regression coefficient $(0.9208)$ further supports the predominance of monolayer adsorption.

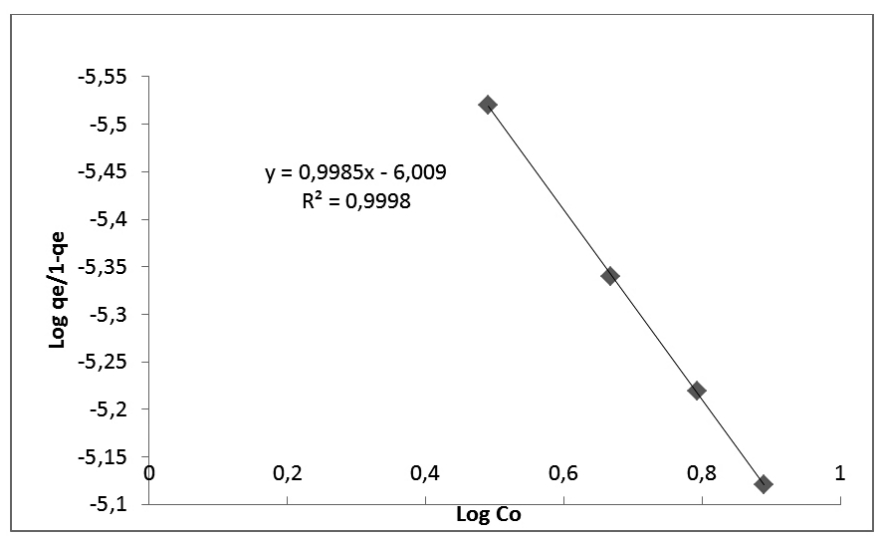

Figure 19: Hill isotherm model plot for the sorption of MEB onto ARHB.

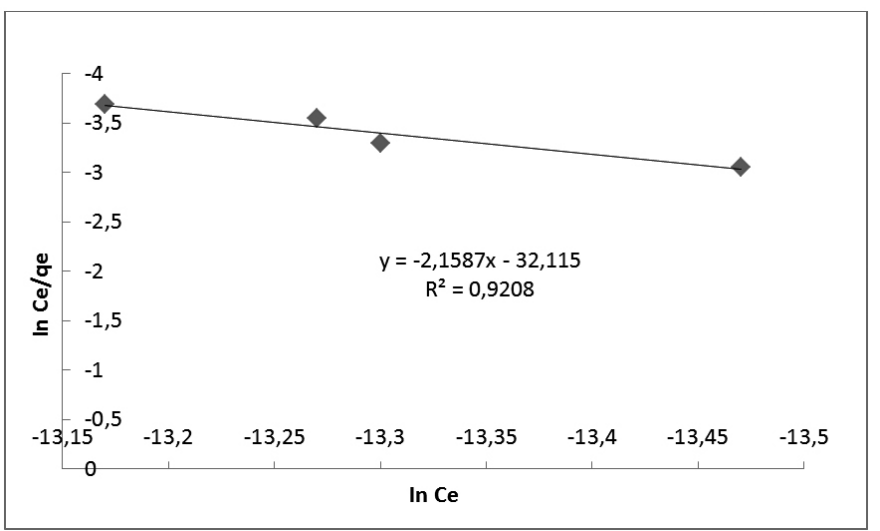

Figure 20: Redlich-Peterson isotherm model plot for the sorption of MEB onto ARHB.

\section{Kinetic models}

Pseudo-first- order model

Adsorption of adsorbate from solution applied to Lagergren pseudo-firstorder rate equation $12^{[5]}$.

$$
\log (\mathrm{qe}-\mathrm{qt})=\log q e-\left(\frac{k_{I}}{2.303}\right) t
$$

The linear form of the pseudo-first order kinetic model is shown in equation and Table 2 with $t$ as time of contact ( $\mathrm{min}$ ), qt is quantity of MEB adsorbed at time $t$, qe is quantity of MEB adsorbed at equilibrium $(\mathrm{mg} / \mathrm{g}), \mathrm{K}_{1}$ pseudo first order rate constant. As shown in Table 5 and linear plots in Figure 10, the data have low regression coefficient $\left(\mathrm{R}^{2}\right)$ of 0.6746 and low value of $\mathrm{K}_{\mathrm{I}}$ as $0.65 \mathrm{~min}^{-1}$ and as such the further discussion on the model and the figure was suspended.

\section{Pseudo-second-order kinetic model}

The assumption in pseudo-second-order kinetic model is that chemisorption dictates the rate controlling step as illustrated in equation $13{ }^{[40]}$.

$$
t / q t=1 / K_{2} q e^{2}+t / q e
$$

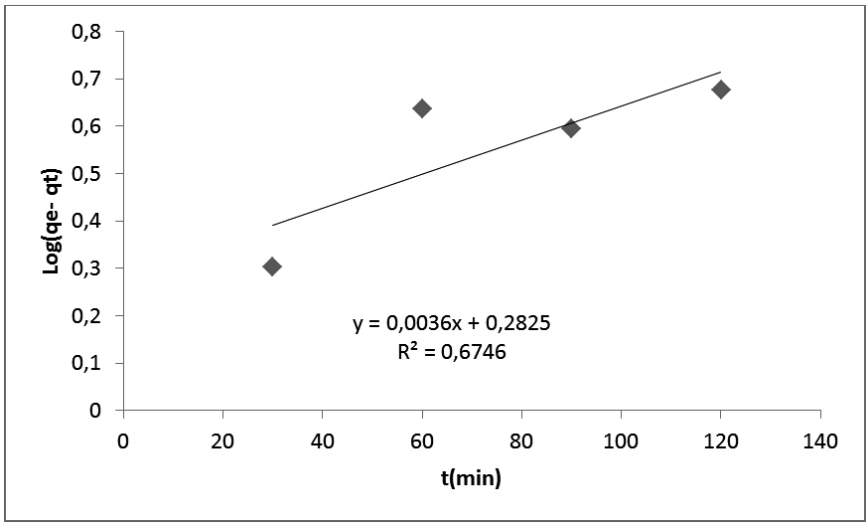

Fig 21: Pseudo-first -order kinetic plot for the adsorption of MEB onto activated rice husk biochar.

where $\mathrm{K}_{2}$ is second order rate constant $(\mathrm{g} / \mathrm{mg} \min )$ and qe adsorption capacity at equilibrium evaluated as intercept and slope of the linear plot of $\mathrm{t} / \mathrm{qt}$ versus $\mathrm{t}$ (Figure 22). The regression coefficient $\left(\mathrm{R}^{2}\right)(0.8285)$ (Figure 22) indicates a good relationship between the parameters and shows that pseudosecond -order model simulates the data better than the pseudo first order kinetic model. Based on the result of the error analysis using sum square of errors, average relative error, coefficient of non- determination, standard error of estimate, non- linear chi square test and Marquardts percentage standard deviation with their equations shown in Table 3 , observation was made that pseudo second order model could not simulate the data as good as intraparticle, liquid film and Elovic kinetic models.

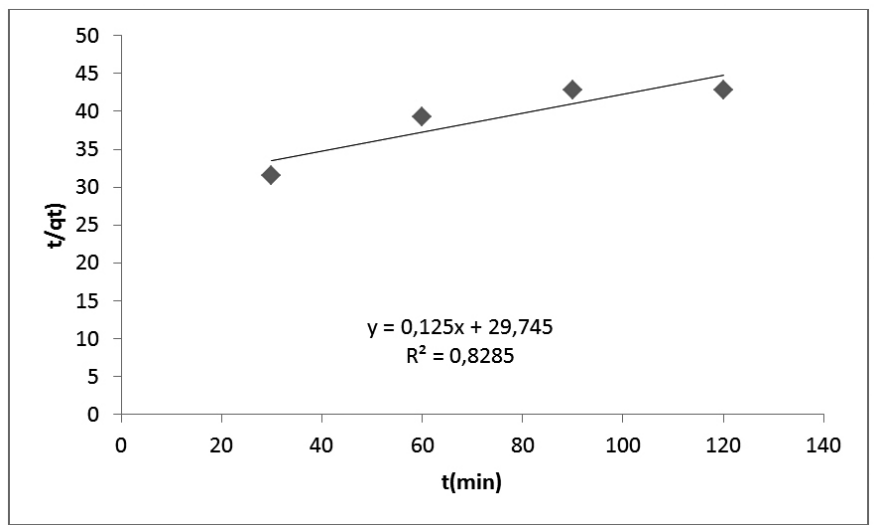

Pseudo second order

Fig 22: Pseudo -second -order kinetics plot for the adsorption of MEB onto activated rice husk biochar.

Elovic kinetic model

Chemisorption of gas onto solid sorbents as described by Elovic kinetic model is represented in equation $14^{[5,18]}$ as shown in Table 2.

$$
\mathrm{q}_{t}=\frac{1}{\beta} \operatorname{In}(\alpha \beta)+\frac{1}{\beta} \operatorname{In}(t)
$$

The constants $\alpha$ and $\beta$ represents Elovic constants for initial adsorption rate $\left(\mathrm{mg} / \mathrm{gmin}^{-1}\right)$ and the degree of surface coverage and activation energy for chemisorption $(\mathrm{g} / \mathrm{mg})$ respectively. From Table 5 and Figure 23, the slope and intercept of the linearized plot of $\mathrm{q}_{\mathrm{t}}$ versus In $\mathrm{t}$ are 0.88 and 0.78 respectively and the regression coefficients from the simulated data was high and of good fitting $\left(\mathrm{R}^{2}=0.9459\right)$. These values suggested that diffusion could be part of the rate limiting step an indication that parameters in Elovic kinetic model supports chemisorption as part of the rate limiting step and prevails at negligible desorption rate ${ }^{[5]}$. From the result of error analysis (Table 5) and in relation to other kinetic models studied, Elovic model could not simulate the data perfectly well and further explanation on this model is suspended. 


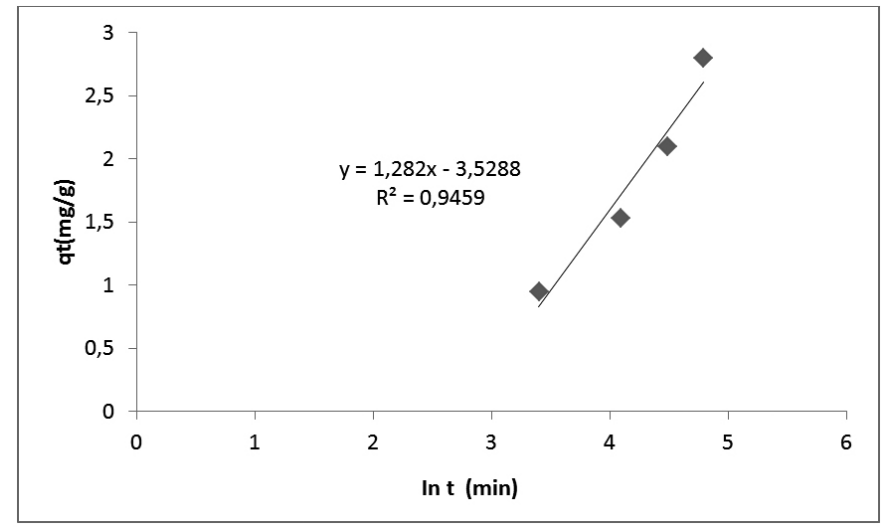

Fig 23: Elovic kinetic plot for the adsorption of MEB onto activated rice husk biochar.

Weber and Morris intraparticle diffusion model

The kinetic data were subjected to Weber and Morris intraparticle diffusion model with its linearized form equation $15^{[27]}$ and shown in Table 2.

$$
q t=K_{I} t^{1 / 2}+C
$$

where $\mathrm{K}_{\mathrm{I}}$ (slope) and $\mathrm{C}$ the intercept represents the intraparticle diffusion rate constant $\left(\mathrm{mg} / \mathrm{g} \min ^{1 / 2}\right)$ and a constant related to the thickness of the boundary layer respectively evaluated from the linear plot of qt versus $\mathrm{t}^{1 / 2}$ and values shown in Table 5. The model has the highest regression coefficient $\left(\mathrm{R}^{2}\right)$ of 0.979 but the value of $\mathrm{C}$ an indication of how high or low an adsorption capacity was very low (Table 5) and could not justify intraparticle diffusivity of the adsorbate through the biosorbent surface. Similarly, From Figure 24, the plot though linear but never passed through the origin a confirmation that intraparticle diffusion was involved in the adsorption but not the only rate determining process ${ }^{[48]}$. Consequently, the failure of the intercept line to pass through the origin could be the involvement of boundary layer control in the adsorption. From the simulation of data using error analysis SSE, $\mathrm{X}^{2}$ and SEE showed poor result for the model whereas ARE gave good result in comparison to other models. This confirms the partial involvement of the model in the mechanism of sorption.

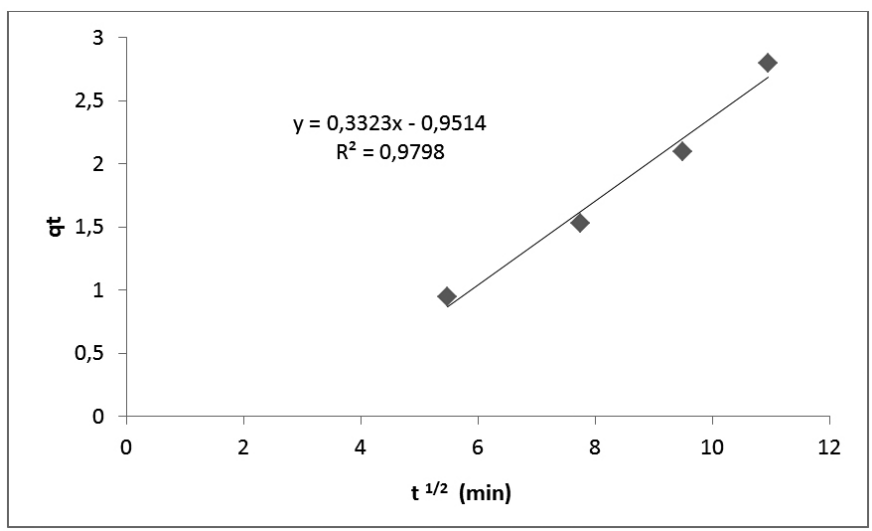

Figure 23: Weber and Morris intraparticle diffusion model for the adsorption of MEB onto activated rice husk biochar.

\section{Liquid film diffusion kinetic model}

The contact between the biosorbent and liquid films of the adsorbate could be a controlling force in adsorption as modeled in equation $16^{[5,43]}$ and in Table 2. The contact between the sorbent and MEB caused migration of the dye from bulk solution to liquid film surface. The diffusion barrier exerted could to a great extent determine the degree of involvement of film diffusion. Consequently the rate of adsorption has been shown to be determined by internal and external diffusion or both. Internal diffusion controls migration of solute materials from external adsorbate surface to internal pore surface of sorbent whereas the external takes care of solute specie movement from to liquid phase boundary layer from the bulk solution ${ }^{[43]}$. The steps could involve film diffusion where adsorbates migrate to external surface of the sorbent, particle diffusion where adsorbates transfer within the pores of the sorbent or sorption of adsorbate at interior surface of the sorbent.

The first two steps are only feasible since the last step proceeds at a very fast rate and may not be considered as a rate determining step. The feasibility of the two steps projects three mechanistic approaches ${ }^{[39,40]}$

i. External movement $>$ internal movement; particle diffusion been prevalent

ii. External movement $<$ internal movement; film diffusion been prevalent

iii. External movement internal movement; significance of rate not felt with adsorbent molecules surrounding liquid film at boundary layer.

$$
\operatorname{In}\left(1-\frac{q t}{q e}\right)=-K_{l f} t
$$

A plot of $\operatorname{In}\left(1-\frac{q t}{q e}\right)(1)$ versus $t$ gave the slope as $\mathrm{K}_{\mathrm{lf}}$ representing the liquid diffusion constant $(1 / \mathrm{min})$ a measure of the transfer coefficient due to external mass on the system. From Figure 24 and Table 5, the intercept and slope were given as 1.01 and -0.0008 respectively with high regression coefficient $\left(\mathrm{R}^{2}\right)$ of 0.968 . Simulation of the data for error analysis indicated that the mode has the lowest value for SSE, SEE and $\mathrm{X}^{2}$ (Table 5) error testing implicating liquid diffusion as part of the rate limiting step. The result confirms that liquid film diffusion was probably a major player in the adsorption mechanism and confirms existence of boundary layer influence as noted in Weber and Morris intraparticle diffusion evaluation. The transport of MEB from the solution to the pores of the adsorbent could be prevalent in the sorption process.

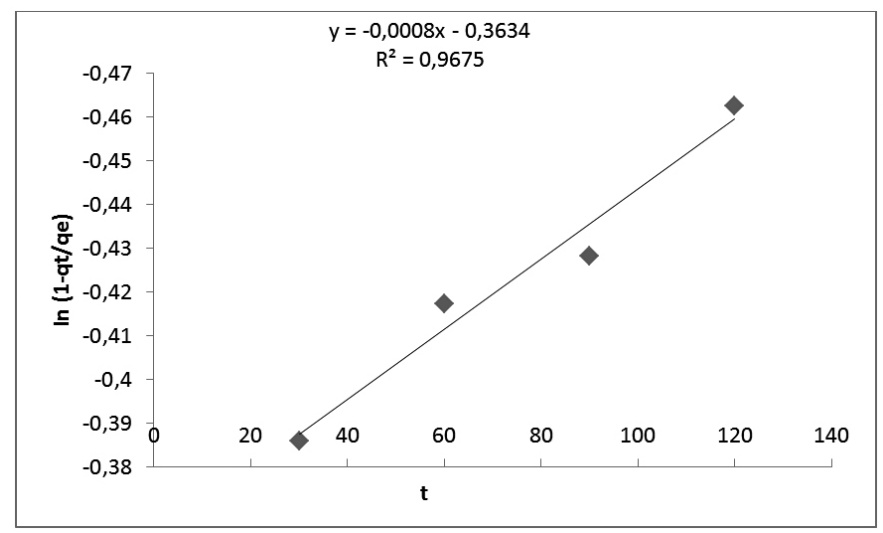

Figure 24: Liquid film diffusion model for the adsorption of MEB onto activated rice husk biochar.

Bangham's pore diffusion model

The linear form of the Bangham's pore diffusion model is represented in equation 17 and Table $2^{[16,46]}$

$$
\log \log \left\{\frac{\text { Co }}{\text { Co-mqt }}\right\}=\log \left\{\frac{m K_{B}}{2.303 V}\right\}+\delta \beta \log t
$$

where Co is the initial metal ion concentration $(\mathrm{mg} / \mathrm{L}), \mathrm{V}$ is volume of solution $(\mathrm{mL}), \mathrm{m}$ the weight of adsorbent $(\mathrm{g} / \mathrm{L}), \Delta \beta$ and $\mathrm{K}_{\mathrm{B}}$ are constants obtained as slope and intercept of the linear plot of $\log \log [\mathrm{Co} / \mathrm{Co}-\mathrm{mqt}]$ versus $\log \mathrm{t}$ ( Figure 25). The plot as shown in Figure 25 was linear with poor regression coefficient $\left(\mathrm{R}^{2}\right)$ of 0.764 indicating that the kinetic model may not have followed pore diffusion. Since the coefficient of regression was not up to the set boundary layer condition, the data was not subjected to simulation using this model for error analysis and further discussion on the model over ruled. 
Table1: Isotherm models and their linear forms.

\begin{tabular}{|c|c|c|c|c|}
\hline $\mathrm{S} / \mathrm{N}$ & Type of model & Models & Linear form & Reference \\
\hline 1 & One parameter & Henry & $q_{e}=K H_{E} C_{e}$ & [5] \\
\hline 2 & Two parameter & Langmuir & $\frac{\mathrm{Ce}}{\mathrm{qe}}=\frac{\mathrm{Ce}}{\mathrm{Qm}}+\frac{1}{\mathrm{bQm}}$ & {$[1,14]$} \\
\hline 3 & Two parameter & Freundlich & $\operatorname{In} \frac{q_{e}}{C e}=\operatorname{InK}_{E q_{m}}-\frac{q_{e}}{n q_{m}}$ & {$[2,3]$} \\
\hline 4 & Two parameter & Elovic & $\operatorname{Inq}_{e}=\operatorname{InK} f+\frac{1}{n} \operatorname{InC} e$ & [4] \\
\hline 5 & Two parameter & Temkin & $\mathrm{q}_{e}=\beta \operatorname{In} \mathrm{A}_{t}+\beta \operatorname{In} C e$ & [5] \\
\hline 6 & Two parameter & Jovanovic & $\operatorname{In} q_{e}=\operatorname{In} q_{m}-K_{f} C_{e}$ & [6] \\
\hline 7 & Two parameter & Hill- deBoer & $\operatorname{In}\left[\frac{C_{e}(1-\theta)}{\theta}\right]-\frac{\theta}{1-\theta}=-\operatorname{In} K_{1}-\frac{K_{2} \theta}{R T}$ & [4] \\
\hline 8 & Two parameter & Kiselev & $\frac{1}{C_{e}(1-\theta)}=\frac{K_{i}}{\theta}+K_{I} K_{n}$ & [5] \\
\hline 9 & Two parameter & Harkin-Jura & $\frac{1}{q_{e}^{2}}=\frac{B}{A}-\left(\frac{1}{A}\right) \log C_{e}$ & [5] \\
\hline 10 & Two parameter & Flory-Huggins & $\operatorname{In}\left(\frac{\theta}{C_{0}}\right)=\operatorname{In} K F_{H}+n \operatorname{In}(1-\theta)$ & [5] \\
\hline 11 & Two parameter & Hill & $\log \frac{q_{e}}{q_{H}-q_{e}}=n H \log \left(C_{e}\right)-\log \left(K_{D}\right)$ & [8] \\
\hline 12 & Two parameter & Fowler-Guggenheim & $\operatorname{In}\left[\frac{C_{e}(1-\theta)}{\theta}\right]=-\operatorname{In} K_{F G}+\frac{2 W \theta}{R T}$ & [1] \\
\hline 13 & Two parameter & $\begin{array}{l}\text { Dubinin-Kaganer- } \\
\text { Radushkevich }\end{array}$ & $I n q_{e}=\operatorname{In} q_{m}-\beta \epsilon^{2}$ & [14] \\
\hline 14 & Three parameter & Redlich-Peterson & $\operatorname{In}\left(\frac{C_{e}}{q_{e}}\right)=\beta \operatorname{In} C_{e}-\operatorname{In} A$ & [5] \\
\hline
\end{tabular}




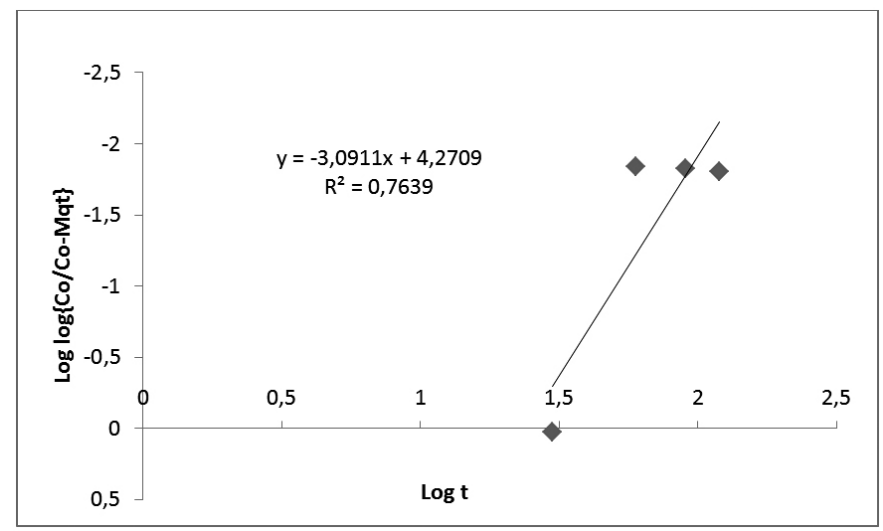

Figure 25: Banghams pore diffusion model for the adsorption of MEB onto activated rice husk biochar.

Table 2: Kinetic models, linear forms and plots.

\begin{tabular}{|c|c|c|c|}
\hline $\mathrm{S} / \mathrm{N}$ & Kinetic models & Linear form & Reference \\
\hline 1 & Pseudo-First order & $\operatorname{In}(\mathrm{qe}-\mathrm{qt})=\operatorname{In} q e-k_{I} t$ & {$[12]$} \\
\hline 2 & Pseudo-second order & $\frac{t}{q_{t}}=\frac{1}{K_{2}} q_{e}{ }^{2}+\frac{t}{q_{e}}$ & \\
\hline 3 & Elovic & $\mathrm{q}_{t}=\frac{1}{\beta} \operatorname{In}(\alpha \beta)+\frac{1}{\beta} \operatorname{In}(t)$ & \\
\hline 4 & Weber and Morris & $q t=K_{I} t^{1 / 2}+C$ & {$[12]$} \\
\hline 5 & Liquid film diffusion & $\operatorname{In}\left(1-\frac{q t}{q e}\right)=-K_{l f} t$ & \\
\hline 6 & Bangham pore diffusion & $\log \log \left\{\frac{\operatorname{Co}}{\operatorname{Co}-m q t}\right\}=\log \left\{\frac{\mathrm{m} K_{B}}{2.303 V}\right\}+\delta \beta \log t$ \\
\hline
\end{tabular}

Table 3: Error analysis and their mathematical equations

\begin{tabular}{|c|c|c|c|}
\hline $\mathrm{S} / \mathrm{N}$ & Kinetic models & Linear form & Reference \\
\hline 1 & Sum square of errors(SSE) & $\sum_{i=1}^{1}\left(\mathrm{q}_{e}, \mathrm{l}, \mathrm{calc}-\mathrm{q}_{e}, \mathrm{l}, \exp \right)$ & [7] \\
\hline 2 & Average relative error(ARE) & $\frac{100}{n} \sum_{i=1}^{1}\left\{\frac{\mathrm{q}_{e}, \mathrm{l}, \mathrm{calc}-\mathrm{q}_{e}, \mathrm{l}, \exp }{\mathrm{q}_{e}, \mathrm{l}, \exp }\right\}$ & [7] \\
\hline 3 & Coefficient of determination $\left(\mathrm{R}^{2}\right)$ & $\frac{\sum\left(\mathrm{q}_{e} \text { calc }-\mathrm{q}_{e} \text { exp }\right)^{2}}{\sum\left\{\left(\mathrm{q}_{e} \text { calc }-\mathrm{q}_{e} \exp \right)^{2}+\mathrm{q}_{e} \text { calc }-\mathrm{q}_{e} \text { exp }\right\}^{2}}$ & [11] \\
\hline 4 & Coefficient of non- determination (CND) & $1-\mathrm{R}^{2}$ & [8] \\
\hline 5 & Standard error of estimate(SEE) & $\left\{\frac{\left(\mathrm{q}_{e} \text { calc }-\mathrm{q}_{e} \text { exp }\right)^{2}}{\mathrm{n}-\mathrm{p}}\right\}^{0.5}$ & [9] \\
\hline 6 & $\begin{array}{l}\text { Marquardts percent standard } \\
\text { deviation(MPSD) }\end{array}$ & $100\left(\frac{1}{n-P} \sum\left\{\frac{\mathrm{q}_{e}, \mathrm{l}, \text { calc }-\mathrm{q}_{e}, \mathrm{l}, \exp }{\mathrm{q}_{e}, \mathrm{l}, \text { calc }}\right\}^{2}\right)^{0.5}$ & {$[10]$} \\
\hline 7 & Non- linear chi-square test(NLCST) & $\sum_{i=1}^{1}\left\{\frac{\left(\mathrm{q}_{e} \text { calc }-\mathrm{q}_{e} \exp \right)^{2}}{\mathrm{q}_{e} \exp }\right\}$ & [11] \\
\hline
\end{tabular}


Table 4: Isotherm model constants and their error analysis.

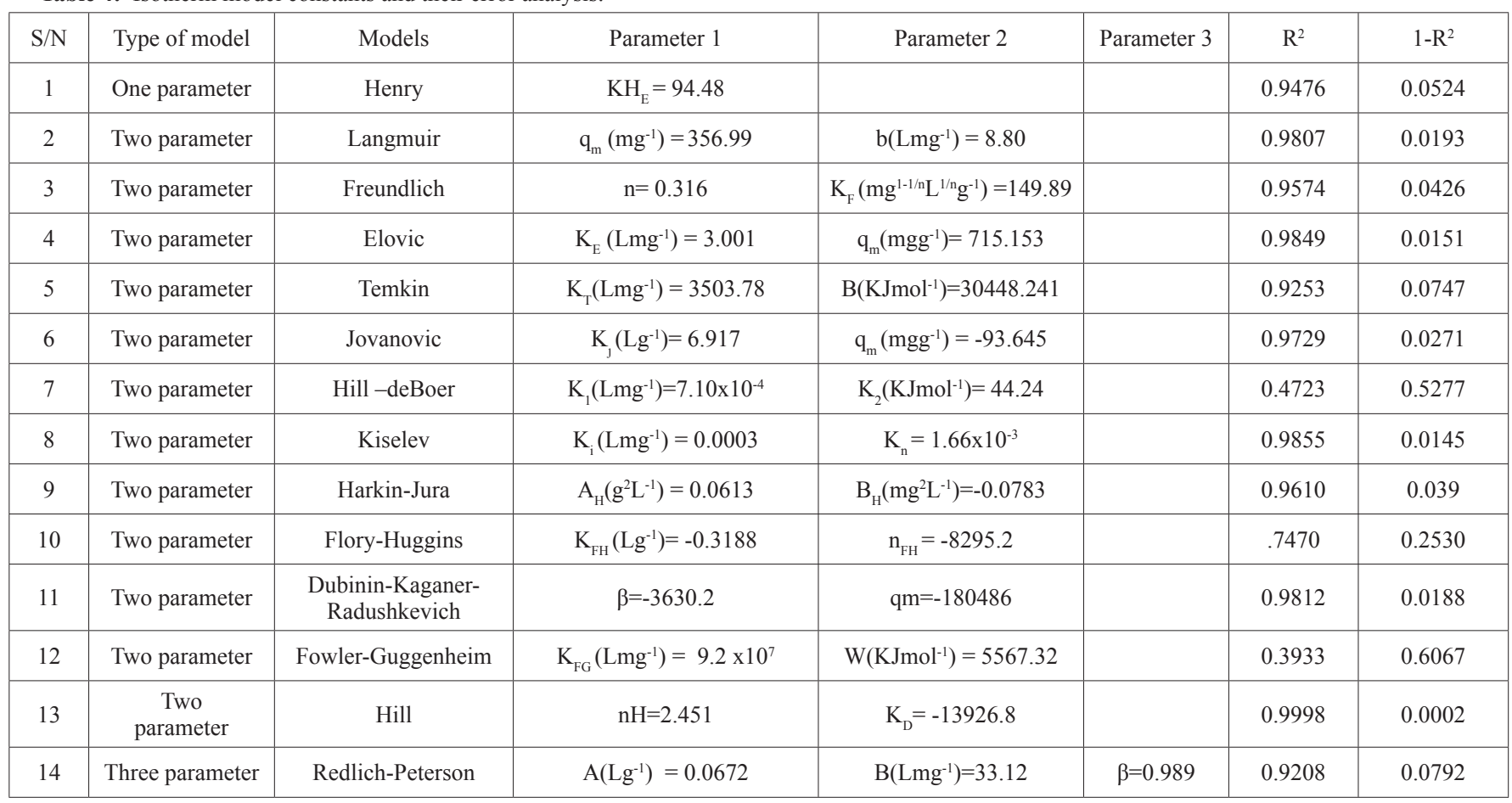

Table 5: kinetic model constants and their error analysis.

\begin{tabular}{|c|c|c|c|c|c|c|c|c|c|c|}
\hline $\mathrm{S} / \mathrm{N}$ & Kinetic models & Constant 1 & Constant 2 & $\mathrm{R}^{2}$ & $\mathrm{X}^{2}$ & SSE & SEE & ARE & MPSD & $1-R^{2}$ \\
\hline 1 & Pseudo-First order & $q_{e}=5.6$ & $\mathrm{~K}_{1}=0.65$ & 0.675 & - & - & - & - & - & - \\
\hline 2 & Pseudo-second order & $\mathrm{q}_{\mathrm{e}}=8.0$ & $\mathrm{~K}_{2=} 2.15$ & 0.829 & $1.17 \times 10^{9}$ & 29.73 & 29.73 & $3.93 \times 10^{7}$ & 99.99 & 0.1715 \\
\hline 3 & Elovic & $\alpha=0.88$ & $\beta=0.78$ & 0.946 & $1.6 \times 10^{7}$ & 3.53 & 3.53 & $1.17 \times 10^{8}$ & 99.99 & 0.0541 \\
\hline 4 & Weber and Morris & $\mathrm{C}=-0.95$ & $\mathrm{~K}_{2}=0.33$ & 0.979 & $1.19 \times 10^{6}$ & 0.951 & 0.951 & $1.25 \times 10^{6}$ & 99.99 & 0.0202 \\
\hline 5 & Liquid film diffusion & $K_{\mathrm{lf}}=-0.0008$ & $\mathrm{qe}=1.01$ & 0.968 & $1.74 \times 10^{5}$ & 0.363 & 0.363 & $1.2 \times 10^{7}$ & 99.99 & 0.0325 \\
\hline 6 & Bangham pore diffusion & $\Delta \beta=4.27$ & $\mathrm{~K} \beta=1.87$ & 0.764 & - & - & - & - & - & - \\
\hline
\end{tabular}

Key: $\mathrm{K}\left(\mathrm{min}^{-1}\right), \mathrm{q}_{\mathrm{e}}\left(\mathrm{mgg}^{-1}\right)=\mathrm{K}_{2}\left(\mathrm{gmg}^{-1} \mathrm{~min}^{-1}\right), \mathrm{K}_{\mathrm{i}}\left(\mathrm{mgg}^{-1} \mathrm{~min}^{-1 / 2}\right), \alpha\left(\mathrm{mgg}^{-1} \mathrm{~min}^{-1}\right), \beta\left(\mathrm{gmg}^{-1}\right)$.Note: Boundary condition was assumed that $\mathrm{R}^{2}$ value for a model must be up to 0.800 to be subjected to error analysis.

\section{CONCLUSION}

Based on the result of this study, the following conclusions were drawn Activated rice husk biochar was prepared and characterized for surface activity and result indicated amorphous nature suitable for adsorption of particulates.

The activated rice husk biochar based on the maximum adsorption capacity has shown strong potential to capture MEB from solutions

The adsorption of MEB onto activated rice husk biochar increases with increase in initial concentration of adsorbate and time of contact until equilibrium. The maximum percentage adsorbed was obtained at $\mathrm{pH}$ of 8 and minimum at $\mathrm{pH} 3$.

Equilibrium of adsorption was studied and the result indicated that Hill isotherm model best described the adsorption equilibrium.

Kinetics study for the adsorption of MEB onto ARHB was observed to follow Weber and Morris intraparticle diffusion and liquid film diffusion mechanisms as the rate limiting step with significant boundary layer condition in operation.

Error analysis was performed to strengthen the result obtained from the kinetic models and to test the applicability of the models in industrial designs. The error analysis was significant in determining the best fit kinetic model
The study presented activated rice husk biochar as an effective, efficient, benign and cheap alternative biosorbent for the sequestration of dye (MEB) from solutions.

\section{REFERENCES}

1. S.Banerjee, S, M.C, Chattopadyaya. Arabian Journal of Chemistry. 10,S1629, 2017

2. E. Betiku, O.A. Sheriff, O.A, Industrial crops and products. 53,314,2014

3. B. Badis, Z. Benmaamar, O. Benkortbi, H. Boutoumi, H. Hamitouche, A. Aggoun, Chemistry Journal of Moldova. General, industrial and Ecological Chemistry. 11,74, 2016.

4. N.B. Prakash, V. Sockan, P. Jayakaran. International Journal of Engineering Science and Innovative Technology. 3,479, 2014.

5. M. Petrovic, J. Rarjenovic, D. Barceló. The Holistic Approach to Environment. 1, 63, 2011.

6. A. Cesaro, V. Naddeo, V. Belgiorno. Journal of Bioremediation and Biodegradation. 4, 1,2013.

7. J.A. Prince, S. Bhuvana, V. Anbharasi, N. Ayyanar, K.V. Boodhoo, G. Singh. Scientific reports. 4, 365,2014

8. N.T. Abdel-Ghani, G.A. El-Chaghaby, F.S. Helal. Global Journal of 
Environmental Science and Mnagement. 2, 209,2016.

9. N. Ayawei, A.N. Ebelegi, D. Wankasi. Journal of Chemistry. 3039817. 2017.

10. R.P. Mokkapati, V.N. Ratnakaram, J.S. Mokkapati. Int, J. Environ. Sci. Technol. 10, 017,2017.

11. R. Farouq, N.S. Yousef. Inter. jour . Cem Eng and Appl. 6, 319, 2015

12. M. Inyang, B. Cao, P. Pullammannappallil, A.R. Zimmerman. Sep.Sci. Technol. 46, 1950,2011

13. I.K.Mazhar,Q.M.Saima, P. Sajida, Y.K. Muhammed. Pak. J. Anal Environ. Chem. 15, 35,2014

14. Q. Hamdaoui, E. Naffrechoux. Journal of Hazardous Materials. 147, $381,2007$.

15. H. Shahbeig, N. Bagheri, S.A. Ghorbanian, A. Halljisani, S. Poorkarimi. Int, J. Environ. Sci. Technol. 4, 243,2013.

16. S. Idris, Y.A. Iyaka, M.M. Ndamitso, E.B. Mohammed, M.T. Umar American Journal of Chemistry. 1, 47.,2017

17. C. Chen. The open chem Engineer Journal. 7,24,2013

18. J.A. Udoji, E.E. Etim. International Journal of Environmental Science and Development. 6, 205, 2015.

19. S. Alkan, M. Caliskan, I. Irenede, .R. Kul. J.Chem.Soc.Pak. 40, 457,2018

20. G. Yang, L. Wu, Q. Xian, F. Shen, J. Wu, Y. Zhang. Plos One. 1,2013

21. D. Ghahremani, I. Mobasherpour, S.A. Mirhosseini. Bulletin de la societe Royale des sciences de Liege.86, 96, 2017.

22. J. Singh, N.S. Mishra, S.I. Banerjee, Y.C. Sharma. bioresources. 6, 2732, 2011.

23. P. Sampranpiboon, P. Charnkeitkong. International journal of energy and environment. 4, 88-98, 2011

24. S.M. Yakout, E. Elsherif. Carbon- Sci. Tech. 1, 144, 2010.

25. S. Patil, V. Deshmukh, S. Renukdas, N. Patel. International journal of Environmental Sciences. 6, 1123, 2011.

26. T. Elmorsi, Journal of Environmental Protection. 2,362, 2007.
27. T. Mahmood, M. Aslam, A. Naeem, T. Sissique, S. Din. Chil. Chem. Soc. $63,3855,2018$

28. O.T. Okareh, A.T. Adeolu. British journal of Applied Science and Technology. 8,267,2015

29. B. Acemioglu, B. Chem Eng J. 106,73,2005

30. O. Ozdemir, B. Armagan, M.S. Turan, M.S. Celik. Dyes and pigments. $62,49,2004$

31. I.O.Saheed, F.A. Adekola, G.A. Olatunji. JOTCSA, 4, 375,2017.

32. P. Guyon, G.P. Frank, M. Science. 323, 495,2009.

33. G.R. Van der Werf, J.T. Randerson, L. Giglio, G.J. Collatz, P.S. Kassibhatla, A.F.Arellano Atmos Chem Phys. 6,3423,2006

34. A. Irwin. Globe Change. 83,8,2014

35. O. Paris, C. Zollfrank, G.A. Zickler, Carbon. 43, 53,2005

36. Y.Yao, B. Gao, M. Inyang, A.R. Zimmerman, X. Cao, P. Pullammanappallil, L. Yan. J. hazard. Mater.190, 501,2011.

37. L.D. Tiwari, L. Lee. Environmental Engineering Research. 17,541-548, 2012.

38. A. Kezerle, N. Velic, D. Hasenay, D.Kovacevic. Croat. Chem. Acta. 91,53, 2018

39. N. Nasuna, B.H. Hameed, A.T.M. Din. J. Hazard. Mater. 175, 126, 2010

40. A. Demirbas. Journal of Analytical and Applied Pyrolysis. 72, 243, 2003.

41. H. Cherifi, B. Fatiha, H. Salah. Appl Surf Sci. 282, 52,2003

42. M. Wawrzkiewiez, Z. Hubick . J. Hazard. Master. 164, 502,2009

43. L. Ai, C. Zhang, L. Meng. Chem. Eng. Data. 56, 4217, 2011.

44. M. Uchimiya, S. Chang, K.T. Klasson. Journal of Hazard Mater., 190 432, 2011.

45. X.D. Cao, L. Ma, B. Gao, W. Harris. Environ.Sci.Technol. 43, 3285, 2009

46. A.O. Dada, J.O. Ojediran, A.P. Olalekan. Adv Chem Phys. 9, 103, 2013

47. B. Samiey, F. Ashoori. Chem. Cent.J. 6, 1, 2002

48. J. Bourke, M. Manley-Harris, C. Fushimi, K. Dowaki, T. Nonoura, M.J. Antal. Industrial and Engineering Chemistry Research. 46, 5954, 2007 